$\underline{\text { Short communication }}$

\title{
Simultaneous determination of mycophenolic acid and its acyl and phenol glucuronide metabolites in human serum by capillary zone electrophoresis
}

Kaname Ohyama ${ }^{\mathrm{a} *}$, Naoya Kishikawa ${ }^{\mathrm{b}}$, Hiroo Nakagawa ${ }^{\mathrm{a}}$, Naotaka Kuroda ${ }^{\mathrm{b}}$, Masaharu Nishikido $^{c}$, Mugen Teshima ${ }^{\mathrm{a}}$, Hideto To ${ }^{\mathrm{a}}$, Takashi Kitahara ${ }^{\mathrm{a}}$, Hitoshi Sasaki ${ }^{\mathrm{a}}$

${ }^{a}$ Department of Hospital Pharmacy, Nagasaki University Hospital of Medicine and Dentistry

b Graduate school of Biomedical Sciences, Course of Pharmaceutical Sciences, Nagasaki University

${ }^{c}$ Division of Nephro-Urology, Department of Translational Medicine, Graduate school of Biomedical Sciences, Nagasaki Univeristy

* Corresponding author. Department of Hospital Pharmacy, Nagasaki University Hospital of Medicine and Dentistry, Nagasaki, Japan. Tel.: +81-95-819-7248; fax: +81-95-819-7251. E-mail address: k-ohyama@nagasaki-u.ac.jp

Keywords: capillary zone electrophoresis / mycophenolic acid / acyl glucuronide / phenol glucuronide / renal transplant patient 


\begin{abstract}
A simple capillary electrophoretic method was developed for simultaneous determination of mycophenolic acid (MPA) and its metabolites, acyl glucuronide (AcMPAG) and phenol glucuronide (MPAG), in human serum. The method utilized only running buffer in the separation, prior acidification of serum, and extraction with ethyl acetate. Separation was performed by capillary zone electrophoresis using 20 $\mathrm{mM}$ sodium acetate-acetic acid ( $\mathrm{pH} 4.9$ ) as running buffer, applied voltage of $15 \mathrm{kV}$, and UV detection at $217 \mathrm{~nm}$. Each electrophoretic run was completed within $14 \mathrm{~min}$. The optimized method demonstrated good performance concerning specificity, linearity ( $r>0.998$ ), sensitivity (limit of detection: for MPA, $0.10 \mu \mathrm{g} / \mathrm{ml}$; for AcMPAG, 0.10 $\mu \mathrm{g} / \mathrm{ml}$; MPAG, $0.42 \mu \mathrm{g} / \mathrm{ml})$, accuracy $(87-108 \%)$ and precision $(<9.3 \%)$. This method was successfully applied to measurements of MPA, AcMPAG, and MPAG in renal transplant patient samples and could be a useful alternative to HPLC-based methods.
\end{abstract}




\section{Introduction}

Mycophenolic acid (MPA) is widely used as an immunosuppressive agent in the therapeutic protocol after organ transplantation and in treatment of autoimmune disease. To improve its oral absorption, MPA is administered as an ester prodrug mycophenolate mofetil (MMF, Cellcept ${ }^{\circledR}$, Roche Pharmaceuticals) that is completely absorbed and readily hydrolyzed by esterases to MPA. MPA non-competitively, selectively and reversibly inhibits the enzyme inosine monophosphate dehydrogenase and guanosine monophosphate synthesis [1].

MPA undergoes metabolism primarily by the uridine diphosphate glucuronosyl transferase enzyme family at liver, kidney, and intestine [2]. The phenolic MPA glucuronide (MPAG), major metabolite of MPA, is pharmacologically inactive, but can be hydrolysed back to MPA during entrohepatic recirculation [3]. Two further metaolites have been identified, namely the acyl glucuronide (AcMPAG) and the phenolic glucoside of MPA and, of these metabolites, only AcMPAG was found to hold similar concentration-dependent pharmacological action to MPA [4, 5]. Therefore, besides MPA, the quantification of MPAG and AcMPAG is important for monitoring of MMF therapy.

A number of high-performance liquid chromatography (HPLC) methods, using UV detection or mass spectrometry, for determination of both MPA and MPAG have been published [6-13]. Now the papers focused on the quantification of AcMPAG in addition to MPA and MPAG are increasing [14-18] and further rise in attention to simultaneous determination of these three analytes is ensured.

Because of a marked difference in polarity of MPA and its metabolites and a 
potential interference from endogenous compounds in blood sample, HPLC methods often required a gradient elution $[8,11-13,17,19,20]$ or an ion-pair reagent $[6,7,21]$, which made the separation condition and the preparation of mobile phase complicated. Additionally, a slow column equilibration and less reproducibility of separation in HPLC are sometimes caused by the mobile phase including an ion-pair reagent. On the other hand, transplant patients receiving MMF therapy are usually in co-medication with many drugs such as other immunosuppressive drugs, antifungal drugs, and antimicrobial drugs. The interference of these agents with the peaks of MPA and the glucuronide metabolites in chromatogram can occur. From these points of view, a novel assay method, which is based on the different separation principle with liquid chromatography, will be desired.

Capillary electrophoresis (CE) is rapidly developing as an alternative analytical tool with different separation mechanism to HPLC [22]. The main attractions of CE are its high efficiency, no need of organic solvent for separation, extremely low solvent consumption compared with HPLC, small sample volume requirement, and ease of automation. Among commonly used modes of CE, capillary zone electrophoresis (CZE) is the simplest mode and can be accessed by only altering buffer composition. Up to date, only one group reported a clinical analysis of MPA and MPAG by CE [23], however, the quantification of AcMPAG was out of scope in this work. Besides its pharmacological activity, AcMPAG has the toxicological effect that may contribute to the gastrointestinal side effects such as diarrhea [24] and the different pharmacokinetics with MPA [17]. Therefore, determination of AcMPAG is informative for not only improving outcome but also reducing side effects in immunosuppressive therapy by 
MMF.

The present study proposed the CZE method for simultaneous determination of MPA, AcMPAG, and MPAG in human serum. Except for HPLC methods, this is the first report demonstrating simultaneous determination of these three analytes.

\section{Materials and methods}

\subsection{Chemicals}

MPA, AcMPAG, MPAG, and the carboxybutoxy ether of MPA (MPAC, internal standard [IS]) were generous gifts from Roche Palo Alto LLC (Palo Alto, CA, USA). Sodium tetraborate, potassium dihydrogen phosphate, sodium acetate, acetic acid, sodium hydroxide, phosphoric acid, hydrochloric acid, and sodium dodecyl sulfate were purchased from Wako (Osaka, Japan). Blank human serum was purchased from Funakoshi (Tokyo, Japan). Acetonitrile and ethyl acetate was obtained from Nacalai Tesque (Kyoto, Japan). All chemicals were of analytical grade. Distilled water was obtained using Simpli Lab-UV (Millipore Corporation, Bedford, MA, U.S.A.). Buffers were filtered through a $0.45-\mu \mathrm{m}$ membrane filter (Millipore).

\subsection{Apparatus and electrophoretic conditions}

All the CE experiments were performed on a CAPI-3200 system equipped with a photodiode array detector (Otsuka Electronics, Osaka, Japan). Fused-silica capillaries (75 $\mu$ m i.d. x $375 \mu$ m o.d.) were obtained from Polymicro Technologies (Phoenix, AZ, USA). Total and effective length (from inlet of capillary to detection window) of capillaries used here were $60 \mathrm{~cm}$ and $50 \mathrm{~cm}$, respectively. All the buffers used in this 
study were borate buffer (sodium tetraborate-hydrochloric acid), phosphate buffer (potassium dihydrogen phosphate-sodium hydroxide) and acetate buffer (sodium acetate-acetic acid). New capillaries were first rinsed with $0.1 \mathrm{M}$ hydrochloric acid for $10 \mathrm{~min}, 0.1 \mathrm{M}$ sodium hydroxide for $10 \mathrm{~min}$, and $20 \mathrm{mM}$ borate buffer $(\mathrm{pH} \mathrm{9.0)}$ for 20 min and then left in borate buffer overnight for the equilibration of capillary. At the beginning of each day's work, the capillary was rinsed with $0.1 \mathrm{M}$ sodium hydroxide for $5 \mathrm{~min}$ and a running buffer for $10 \mathrm{~min}$. To achieve reproducible results, the capillary was rinsed with $0.1 \mathrm{M}$ sodium hydroxide for $1 \mathrm{~min}$ and running buffer for $2 \mathrm{~min}$ between runs and, especially in serum sample analyses, the capillary was rinsed with sodium dodecyl sulfate for 2 min before sodium hydroxide. Separation conditions were as follows: applied voltage, $15 \mathrm{kV}$; detection wavelength, $217 \mathrm{~nm}$; temperature, $25^{\circ} \mathrm{C}$; sample injection, vacuum at $50 \mathrm{kPa}$ for $1 \mathrm{~s}$.

\subsection{Stock solutions, calibration standards and quality controls}

Stock solutions of MPA (2 mg/ml), AcMPAG (1 mg/ml), and MPAC $(0.5 \mathrm{mg} / \mathrm{ml})$ were prepared in acetonitrile and stored at $-20^{\circ} \mathrm{C}$. MPAG stock solution $(5 \mathrm{mg} / \mathrm{ml})$ was prepared in acetonitrile-water $(50: 50, \mathrm{v} / \mathrm{v})$ and stored at $-20^{\circ} \mathrm{C}$. These stock solutions were diluted by acetonitrile for MPA and AcMPAG and with acetonitrile-water for MPAG to prepare working solutions.

$540 \mu \mathrm{l}$ Drug-free serum acidified with $10 \mu \mathrm{l}$ phosphoric acid $(850 \mathrm{~g} / \mathrm{l})$ was transferred into Eppendorf tube and then, was spiked with each working solution (total volume of $600 \mu \mathrm{l}$ ) to yield calibration standards.

The preparation of quality control samples at three different concentrations $\left(\mathrm{QC}_{\text {low }}\right.$, 
$\mathrm{QC}_{\text {med }}, \mathrm{QC}_{\text {high }}$ : MPA, 0.835, 9.98, $46.4 \mu \mathrm{g} / \mathrm{ml}$; AcMPAG, 0.835, 5.01, $17.5 \mu \mathrm{g} / \mathrm{ml}$; MPAG, 8.35, 99.8, $234 \mu \mathrm{g} / \mathrm{ml}$ ) was performed in the same way as calibration standards but they were independent of calibration standards.

\subsection{Clinical samples}

The applicability of the proposed method was assessed on two stable renal transplant patients (Pt. 1 and Pt. 2) receiving MMF therapy (Pt. 1, $250 \mathrm{mg}$ twice a day; Pt. 2, $500 \mathrm{mg}$ at morning and $250 \mathrm{mg}$ at evening). This application study was approved by Ethics Committee of Nagasaki University Hospital and written informed consent was obtained from the patients. Blood samples were collected at $2 \mathrm{~h}$ after the administration of MMF at morning. After the collection, the samples were left for 30 min and centrifuged at 15,000 rpm for $5 \mathrm{~min}$. A $600-\mu \mathrm{l}$ aliquot of the supernatant (i.e. serum) was transferred into Eppendorf tube and acidified with phosphoric acid. The serum samples were stored at $-20^{\circ} \mathrm{C}$ until analysis.

\subsection{Sample preparation}

To calibration standards, QC samples, and patient serum samples, $6 \mu \mathrm{l}$ of MPAC (IS, $0.5 \mathrm{mg} / \mathrm{ml}$ ) was added followed by $1.2 \mathrm{ml}$ of ethyl acetate as a liquid-liquid extraction solvent. The tubes were briefly vortex mixed and centrifuged for $5 \mathrm{~min}$ at 15,000 rpm. The supernatant was then transferred into a clean tube and evaporated to dryness. The residue was reconstituted with $200 \mu \mathrm{l}$ of acetonitrile-water mixture (50:50, v/v ) and an aliquot of it was injected onto CE system. 


\subsection{Assay validation}

Specificity was determined by comparing the migration times of each analyte against the electropherograms of extracted blank serum sample and blank serum sample spiked with only IS.

The linearity of the method was evaluated by processing a six-point calibration curves $(\mathrm{n}=5)$ in the range of $0.40-53 \mu \mathrm{g} / \mathrm{ml}$ for MPA, $0.40-20 \mu \mathrm{g} / \mathrm{ml}$ for AcMPAG, and 5.0-267 $\mu \mathrm{g} / \mathrm{ml}$ for MPAG. The peak area ratios between each analyte and IS were plotted against nominal concentrations. Regression analysis was conducted to determine slope, intercept and correlation coefficient for the evaluation of linearity. The limit of detection (LOD) was defined at signal-to-noise ratio of 3:1.

The precision and accuracy of the method were determined by the analyses of QC samples. Precision (\%) is expressed as coefficient of variation (CV), while accuracy (\%) is expressed as ([measured concentration/nominal concentration] $\mathrm{x}$ 100). The recovery of the extraction procedure was assessed by comparing the peak areas of the extracted $\mathrm{QC}$ samples $\left(\mathrm{QC}_{\text {med }}\right.$ and $\left.\mathrm{QC}_{\text {high }}\right)$ with peak areas of reference standards prepared in acetonitrile-water mixture (50:50, v/v).

\section{Results and discussion}

\subsection{Separation conditions (buffer selection / applied voltage)}

Manipulation of buffer $\mathrm{pH}$ is a key strategy for optimization of the separation of ionizable analytes in CZE because buffer $\mathrm{pH}$ determines the extent of the ionization of each analyte and the magnitude of electroosmotic flow (EOF). In this study, due to the deprotonation of carboxylic acid, MPA, MPAG, AcMPAG, and MPAC are negatively 
charged at $\mathrm{pH}>4.5$. The separation based on the difference of the charge to mass ratio between the analytes can be obtained above $\mathrm{pH}$ 4.5. For EOF, the occurrence of EOF at $\mathrm{pH} 4$ and its magnitude is elevated by an increase in $\mathrm{pH}$. The running buffers such as borate buffer (20 mM, pH 9.0), phosphate buffer (20 mM, pH 6.5), and acetate buffer (20 mM, pH 4.9) were evaluated (Fig. 2). Interestingly, the peak of AcMPAG was shortened when using borate buffer. This phenomenon could be attributed to the hydrolysis of AcMPAG at alkaline condition, which was indicated by Shipkova et al. [14]. To prevent the hydrolysis of AcMPAG, Shipkova and Armstrong insisted of the prior acidification of plasma samples before sample preparation $[14,18]$ while two groups did not recognize a need of it $[15,17]$. Taking into consideration the results obtained by using borate buffer, the current study employed the prior acidification of the serum samples to prevent degradation of AcMPAG. The separation order was dramatically altered by the change of buffer $\mathrm{pH}$ and the increase in $\mathrm{pH}$ made the peaks sharp. All running buffers provided good separation while MPAC and MPAG peaks migrated closely at $\mathrm{pH}$ 6.5. Finally, acetate buffer (20 mM, pH 4.9) was selected for this study.

The effect of applied voltage was studied at 10,15 , and $20 \mathrm{kV}$ using $20 \mathrm{mM}$ acetate buffer at $\mathrm{pH}$ 4.9. The elevation of voltage led to shorter analysis time and sharper peaks, however, the peaks of AcMPAG and MPAC were very close at $20 \mathrm{kV}$. The applied voltage was set at $15 \mathrm{kV}$.

\subsection{Electropherograms}

Fig. 3 (A) and (B) show representative electropherograms of blank serum and blank 
serum containing the IS. The peaks of each component in blank serum were well resolved and also there was no interference from endogenous compounds at the migration times of analytes. Fig. $3(\mathrm{C})$ and (D) show representative electropherograms of blank serum spiked with MPA $(5.0 \mu \mathrm{g} / \mathrm{ml})$, AcMPAG $(3.33 \mu \mathrm{g} / \mathrm{ml})$, and MPAG $(66.7$ $\mu \mathrm{g} / \mathrm{ml}$ ) and serum sample of renal transplant patient (Pt. 1), in which MPA of 5.83 $\mu \mathrm{g} / \mathrm{ml}$, AcMPAG of $1.33 \mu \mathrm{g} / \mathrm{ml}$, and MPAG of $38.9 \mu \mathrm{g} / \mathrm{ml}$ was found, respectively. The peaks were identified by spiking the serum samples with each standard solution. Current medication to each patient was recorded at the time of blood sample collection and included: tacrolimus, methylprednisolone, famotidine, fluvastatin, valsartan, amoxicillin, and nateglinide. No electrophoretic interference was detected from any of these medications.

\subsection{Linearity, sensitivity}

Calibration curves in human serum were linear over the concentration range, based on the peak area ratio of MPA, AcMPAG, or MPAG to the IS. The correlation coefficient $(r)$ was greater than 0.998 in all calibration curves $(n=5)$. The assay parameters consisting of calibration range, slope, intercept, correlation coefficients, and LOD are given in Table 1. The sensitivity of the proposed method was comparable to previously reported HPLC method [15].

\subsection{Accuracy, precision, recovery}

Table 2 summarizes the results for intra- and inter-day accuracy and precision. Assay accuracy and precision were determined by six replicate analyses of QC samples 
( $\mathrm{QC}_{\text {low }}, \mathrm{QC}_{\mathrm{med}}$, and $\mathrm{QC}_{\text {high }}$ ) on a single day (i.e. intra-day) and over six consective days (i.e. inter-day). During the course of method validation, intra- and inter-day precision was less than $10 \%$. The accuracy of MPA, AcMPAG, and MPAG concentrations ranged from $87-102 \%, 88-108 \%, 89-105 \%$, respectively. These data show that the method is both precise and accurate in human serum analysis and met the requirements for bioanalytical analysis [25]. The recoveries (\%) of MPA, AcMPAG, and MPAG were as follows: for MPA, $82.4\left(\mathrm{QC}_{\mathrm{med}}\right), 78.5\left(\mathrm{QC}_{\mathrm{high}}\right)$; for $\mathrm{AcMPAG}, 83.3\left(\mathrm{QC}_{\mathrm{med}}\right), 80.3$ $\left(\mathrm{QC}_{\text {high }}\right)$; for MPAG, $58.1\left(\mathrm{QC}_{\mathrm{med}}\right), 57.5\left(\mathrm{QC}_{\text {high }}\right)$. The lower recovery of MPAG by the extraction procedure may be attributed to the relatively hydrophilic nature of MPAG, which was pointed out by Bahrami and Mohammadi [6].

\subsection{Clinical application}

The concentrations $(\mu \mathrm{g} / \mathrm{ml})$ of MPA, AcMPAG, and MPAG in serum samples obtained from two renal transplant patients were 5.88, 1.33, and 38.9 for Pt. 1 and 2.80, 0.41, and 10.9 for Pt. 2, respectively. The levels of each analyte after the administration of MMF was closely related to kidney function expressed as creatinine clearance (Ccr) [1, 26-28]. In the current study, the concentration of all the analytes in Pt. 1 were higher than those in Pt. 2, which was consistent with the lower value of Ccr in Pt. 1 (Ccr calculated by Cockcroft-Gault Fomula: Pt. 1, 27 ml/min; Pt. 2, 38 ml/min).

\section{Conclusions}

A simple CZE method allowed simultaneous determination of MPA, AcMPAG, and MPAG in human serum and also, was successfully applied for the analysis of serum 
samples from renal transplant patients. This method is a cost-effective way of measuring MPA and its two metabolites in a single run and could be potentially useful as an alternative to HPLC-based methods.

\section{Acknowledgements}

This study was supported by a Grant-in-Aid for Scientific Research from the Ministry of Education, Science, Sports and Culture of Japan. The authors thank Roche Palo Alto LLC for kindly donating standard samples of MPA, AcMPAG, MPAG, and MPAC. Sincere thanks to Ms. Emiko Fujimoto for her technical assistance. 


\section{References}

[1] R.E.S Bullingham, A.J. Nicholls, B.R. Kamm, Clin. Pharmacokinet. 34 (1998) $429-455$.

[2] N. Picard, P. Marquet, Drug. Metab. Dispos. 32 (2004) 1524.

[3] L.M. Shaw, T. Pawinski, M. Korecka, A. Nawrocki, Ther. Drug. Monit. 24 (2002) 68-73.

[4] M. Shipkova, V.W. Armstrong, E. Wieland, P.D. Niedmann, E. Schutz, G. Brenner-Weiss, M. Voihsel, F. Braun, M. Oellerich, Br. J. Pharmacol. 126 (1999), $1075-1082$.

[5] E. Schutz, M. Shipkova, V.W. Armstrong, E. Wieland, M. Oellerich, Clin. Chem. 45 (1999) 419-422.

[6] G. Bahrami, B. Mohammadi, Clin. Chim. Acta. 370 (2006) 185-190.

[7] W.P. Yau, A. Vathsala, H.X. Lou, E. Chan, J.Chromatogr. B 805 (2004), 101-112.

[8] M. Shipkova, P.D. Niedmann, V.W. Armstrong, E. Schutz, E. Wieland, L.M. Shaw, M. Oellerich, Clin. Chem. 44 (1998) 1481-1488.

[9] D. Indjova, L. Kassabova, D. Svinarov, J. Chromatogr. B 817 (2005), 327-330.

[10] K. Wiwattanawongsa, E.L. Heinzen, D.C. Kemp, R.E. Dupuis, P.C. Smith, J. Chromatogr. B 763 (2001), 35-45.

[11] M. Bolon, L. Jeanpierre, M. El Barkil, K. Chelbi, M. Sauviat, R. Boulieu, J. Pharm. Biomed. Anal. 36 (2004) 649-651.

[12] A. Premaud, A. Rousseau, Y. Le Meur, G. Lachatre, P. Marquet, Ther. Drug Monit. 26 (2004) 609-619.

[13] T.M. Annesley, L.T. Clayton, Clin. Chem. 51 (2005) 872-877. 
[14] M. Shipkova, E. Schutz, V.W. Armstrong, P.D. Niedmann, M. Oellerich, E. Wieland, Clin. Chem. 46 (2000) 365-372.

[15] G. Khoschsorur, W. Erwa, J. Chromatogr. B 799 (2004) 355-360.

[16] I.S. Westley, B.C. Sallustio, R.G. Morris, Clin. Biochem. 38 (2005) 824-829.

[17] C.G. Patel, F. Akhlaghi, Ther. Drug Monit. 28 (2006) 116-122

[18] G. Brandhorst, F. Streit, S. Goetze, M. Oellerich, V.W. Armstrong, Clin. Chem. 52 (2006) 1962-1964.

[19] A.E. Mendonza, R.Y. Gohh, F. Akhlaghi, Ther. Drug Monit. 28 (2006) 402-406.

[20] A. Pastore, A. Lo Russo, F. Piemonte, L. Mannucci, G. Federici, J. Chromatogr. B 776 (2002) 251-254.

[21] A. Aresta, F. Palmisano, C.G. Zambonin, P. Schena, G. Grandaliano, J. Chromatogr. B 810 (2004), 197-202.

[22] J.R. Petersen, A.O. Okorodudu, A. Mohammad, D.A. Payne, Clin. Chim. Acta. 330 (2003), 1-30.

[23] S. Unsalan, G. Hempel, J. Boos, G. Blaschke, Chromatographia 54 (2001), 635-637.

[24] E. Wieland, M. Shipkova, U. Schellhaas, E. Schutz, P.D. Niedmann, V.W. Armstrong, M. Oellerich, Clin. Biochem. 33 (2000) 107-113.

[25] Center for Drug Evaluation and Research, Food and Drug Administration. Bioanalytical Method Validation; Guidance for Industry 2001.

[26] H.J. Johnson, S.K. Swan, K.L. Heim-Duthoy, A.J. Nicholls, I. Tsina, T. Tarnowski, Clin. Pharmacol. Ther. 63 (1998), 512-518.

[27] S. Morgera, H.H. Neumayer, L. Fritsche, S. Kuchlinke, D. Lampe, V. Ahnert, S. 
Bauer, I. Mai, K. Budde, Int. J. Clin. Pharmacol. Ther. 36 (1998), 159-163.

[28] M. Shipkova, V.W. Armstrong, L. Weber, P.D. Niedmann, E. Wieland, J. Haley, B.

Tonshoff, M. Oellerich, Ther. Drug Monit. 24 (2002), 390-399. 


\section{Figure caption}

Fig. 1 Chemical structures of mycophenolic acid (MPA), carboxybutoxy ether of MPA (MPAC, IS), and glucuronide metabolites of MPA: acyl glucuronide (AcMPAG) and phenol glucuronide (MPAG).

Fig. 2 Effect of buffer $\mathrm{pH}$ on the separation. Running buffers $(20 \mathrm{mM})$ were as follows: $\mathrm{pH} 9.0$, borate buffer; $\mathrm{pH}$ 6.5, phosphate buffer; $\mathrm{pH} 4.9$, acetate buffer. Other conditions as in section 2.2. Peaks: 1, MPA; 2, AcMPAG; 3, MPAC (IS); 4, MPAG.

Fig. 3 Electropherograms: (A) human blank serum; (B) human blank serum containing IS; (C) human blank serum spiked with MPA (5.0 $\mu \mathrm{g} / \mathrm{ml})$, AcMPAG (3.33 $\mu \mathrm{g} / \mathrm{ml})$, and MPAG $(66.7 \mu \mathrm{g} / \mathrm{ml})$; (D) renal transplant patient serum sample (Pt. 1) at $2 \mathrm{~h}$ after MMF oral administration. Running buffer: $20 \mathrm{mM}$ acetate buffer ( $\mathrm{pH} 4.9$ ). Other conditions as in section 2.2. Peaks: 1, MPA; 2, AcMPAG; 3, MPAC (IS); 4, MPAG. 
Table 1 Assay parameters for determination of MPA, AcMPAG, and MPAG in human serum

\begin{tabular}{lccc}
\hline & MPA & AcMPAG & MPAG \\
\hline Calibration range $[\mu \mathrm{g} / \mathrm{ml}]$ & $0.40-55.3$ & $0.40-20.0$ & $5.00-267$ \\
Linearity & & & \\
$\mathrm{n}$ & 5 & 5 & 5 \\
Slope* $_{\text {Intercept* }}^{*}$ & $0.154 \pm 0.002$ & $0.096 \pm 0.002$ & $0.118 \pm 0.002$ \\
Correlation coefficient & $0.028 \pm 0.022$ & $0.004 \pm 0.008$ & $0.450 \pm 0.150$ \\
$\quad$ LOD $[\mu \mathrm{g} / \mathrm{ml}]$ & 0.9991 & 0.9994 & 0.9981 \\
$*$ Mean + standard error & & 0.10 & 0.42 \\
\hline
\end{tabular}

* Mean \pm standard error

K. Ohyama, et al 
Table 2 Intra-day $(n=6)$ and inter-day $(n=6)$ accuracy and precision for determination of MPA, AcMPAG, and MPAG in human serum

\begin{tabular}{cccccc}
\hline \multirow{2}{*}{$\begin{array}{c}\text { Sample } \\
\text { Analyte }\end{array}$} & \multicolumn{2}{c}{ Intra-day } & & \multicolumn{2}{c}{ Inter-day } \\
\cline { 2 - 3 } \cline { 5 - 6 } & Accuracy $(\%)^{*}$ & Precision $(\mathrm{CV}, \%)$ & & Accuracy $(\%)^{*}$ & Precision $(\mathrm{CV}, \%)$ \\
\hline MPA & & & & & \\
$\mathrm{QC}_{\text {low }}$ & $87.1 \pm 0.45$ & 1.3 & & $102 \pm 3.3$ & 8.2 \\
$\mathrm{QC}_{\text {med }}$ & $93.4 \pm 0.19$ & 0.5 & & $96.3 \pm 1.2$ & 3.1 \\
$\mathrm{QC}_{\text {high }}$ & $97.1 \pm 0.34$ & 0.9 & & $96.9 \pm 1.6$ & 4.1 \\
AcMPAG & & & & \\
$\mathrm{QC}_{\text {low }}$ & $88.4 \pm 0.71$ & 2.0 & & $98.5 \pm 2.4$ & 6.2 \\
$\mathrm{QC}_{\text {med }}$ & $100 \pm 0.32$ & 0.8 & & $102 \pm 2.0$ & 5.0 \\
$\mathrm{QC}_{\text {high }}$ & $108 \pm 0.46$ & 1.1 & & $103 \pm 2.4$ & 5.8 \\
$\mathrm{MPAG}$ & & & & \\
$\mathrm{QC}_{\text {low }}$ & $88.5 \pm 1.8$ & 5.1 & & $94.3 \pm 3.5$ & 9.3 \\
$\mathrm{QC}_{\text {med }}$ & $97.9 \pm 0.67$ & 1.7 & & $102 \pm 2.1$ & 5.3 \\
$\mathrm{QC}_{\text {high }}$ & $105 \pm 0.34$ & 0.8 & & $102 \pm 2.9$ & 7.0 \\
\hline
\end{tabular}

* Mean \pm standard error 
Fig. 1<smiles>COC1=C(C)C2COC(=O)C2C(O)=C1C/C=C(\C)CCC(=O)O</smiles><smiles>COC1=C(C)C2COC(=O)C2C(O)=C1C/C=C(\C)CCC(=O)OC1OC(C(=O)O)C(O)C(O)C1O</smiles>

AcMPAG<smiles>COC1=C(C)C2COC(=O)C2C([O-])=C1C/C=C(\C)CCC(=O)O</smiles>

\section{MPAG}

Pharmacologically inactive<smiles>COC1=C(C)C2COC(=O)C2C(OCCCCC(=O)O)=C1C/C=C(\C)CCC(=O)O</smiles>

MPAC (IS) 
Fig. 2
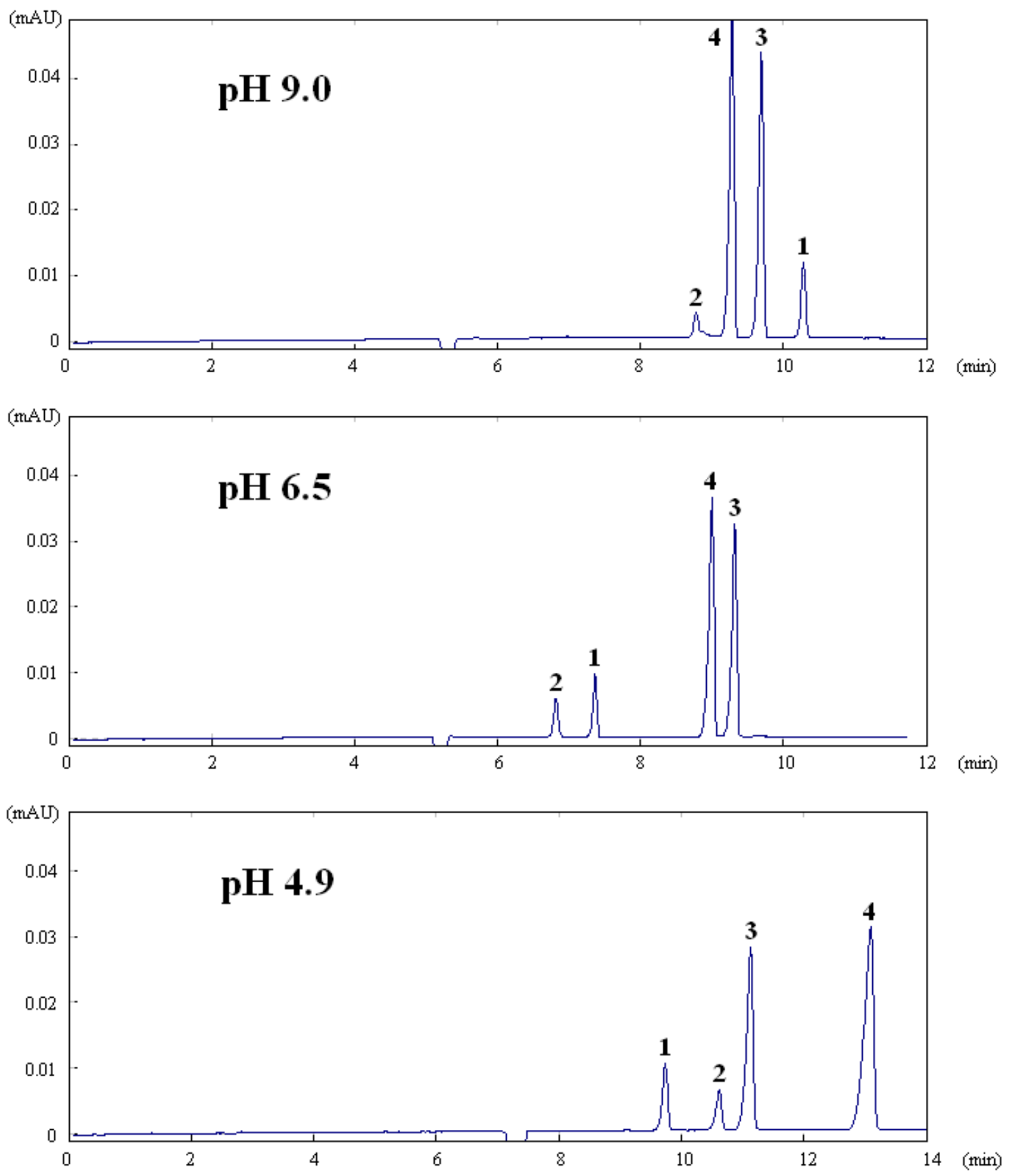

K. Ohyama, et al 
Fig. 3
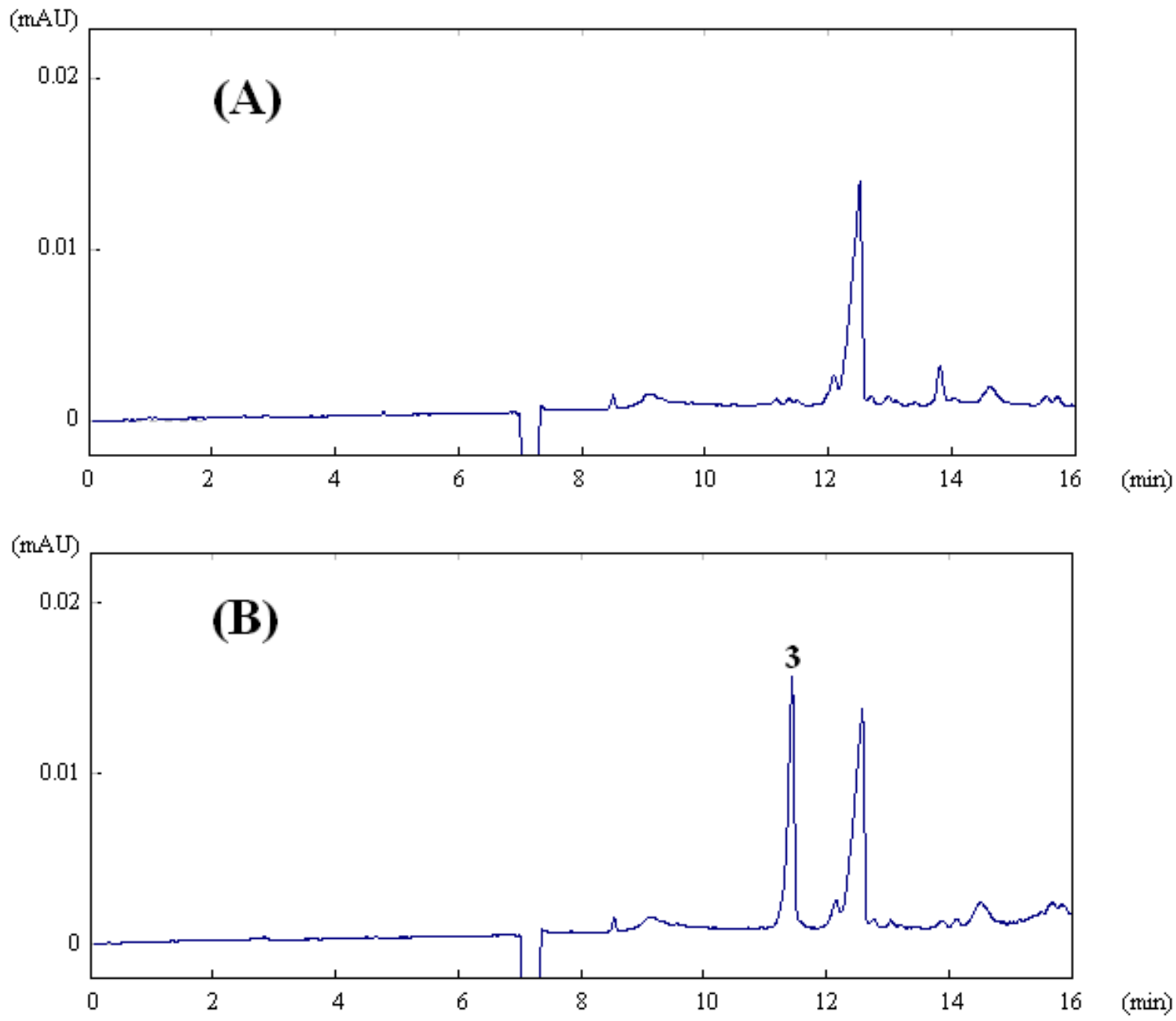

K. Ohyama, et al 
Fig. 3 (continued)
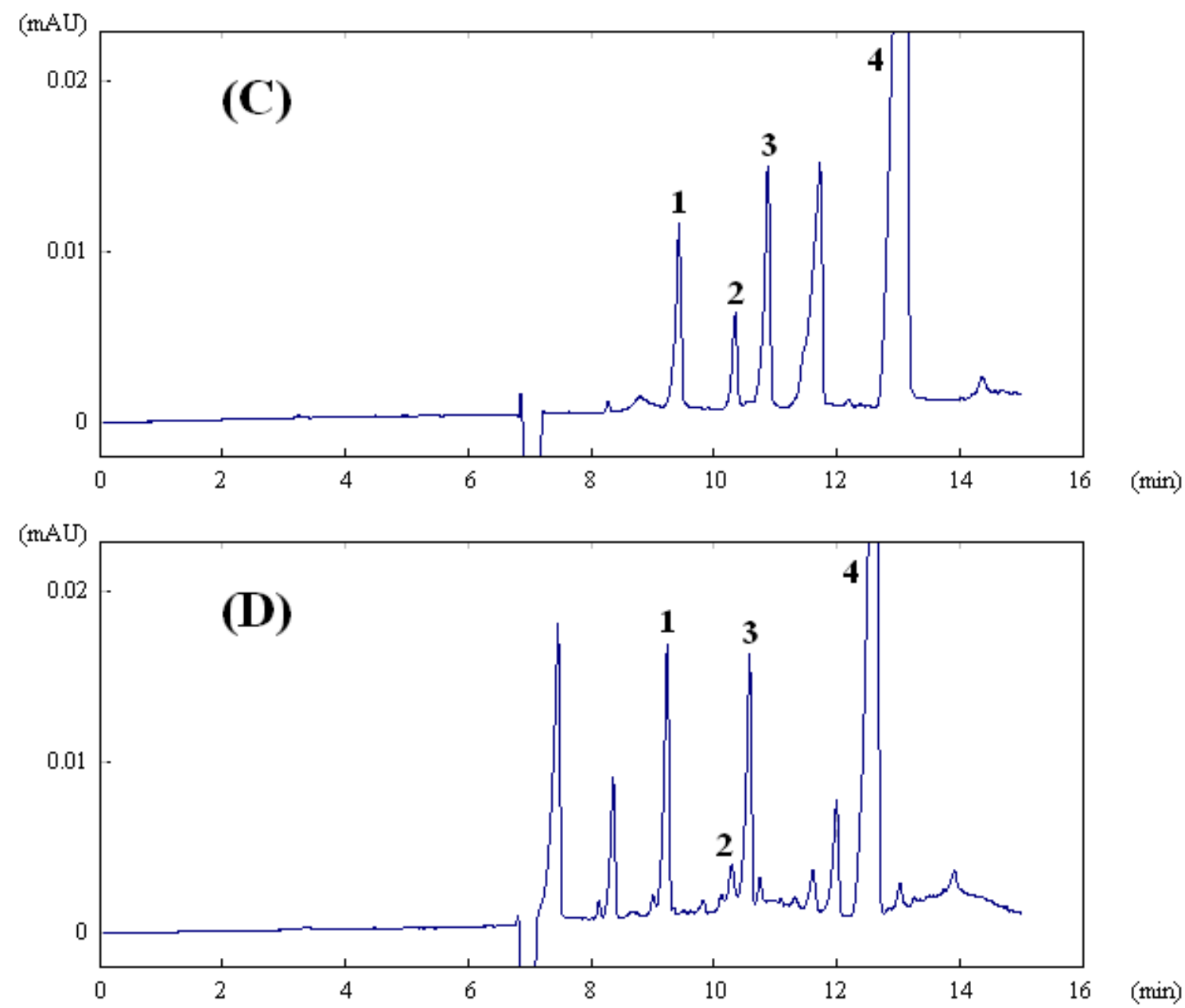

K. Ohyama, et al 